\title{
AS REDES SOCIAIS EM UMA PROPOSTA INTERDISCIPLINAR DE ESTÁGIO SUPERVISIONADO
}

\author{
Jéssica da Silva Rodrigues Cecim ${ }^{1}$ \\ Ráisa Camilo Ferreira ${ }^{2}$ \\ Hellen Ruiz ${ }^{3}$ \\ André Ribeiro ${ }^{4}$ \\ Adilson Grego Junior ${ }^{5}$
}

Práticas interdisciplinares podem/não podem ser a norma. Do nosso ponto de vista, as vivências dessas práticas constituem-se de fato em conquistas de territórios antes desconhecidos e, a partir delas, compartilhados por professore (a)s de disciplinas escolares.

(ROSA, 2007).

\section{Mas, professora ${ }^{6}$, como unir Geografia, Letras, Filosofia e Enfermagem?}

As aulas de estágio foram realizadas em 2015 e, em nosso imaginário, a partir da escolha de uma escola iríamos unicamente acompanhar as aulas de algum professor da nossa área de estudo e provavelmente desenvolver algum tipo de intervenção na escola durante esse período. Acostumados sempre a cursarmos disciplinas com nossos colegas de curso, o primeiro estranhamento se deu ao perceber a sala de aula composta por uma diversidade de pessoas de cursos distintos.

Em consonância com esse quadro inicial em que nos vimos logo na primeira aula da disciplina, Rosa (2007, p. 53) nos traz uma reflexão na qual chama a atenção para um panorama que em professores de diversas disciplinas escolares costumam estabelecer um pertencimento com sua comunidade de origem. A autora nos dá exemplos de associações que são organizadas dentro de um campo de conhecimento e que promovem eventos em sua área de estudo, eventos nos quais estão presentes os professores da educação básica, professores em formação inicial e professores universitários.

Ainda segundo a autora "o acesso aos debates produzidos por essas associações, a frequência aos eventos, o contato com publicações produzidas a partir deles, produzem também outros efeitos que vão compondo tessituras em torno de processos de identificação profissional docente" (Ibdem). Esse panorama nos faz compreender melhor o porquê de alguns estranhamentos logo no início da disciplina de estágio, a qual começou a fazer com que nos deslocássemos um pouco de nossos próprios institutos e colegas de curso.

Ainda no que se refere às nossas impressões iniciais, acreditamos que a maior surpresa veio quando a professora nos apresentou a base da sua proposta de trabalho dentro da disciplina: a interdisciplinaridade. Nos direcionou a montarmos grupos de modo que cada grupo tivesse o maior

\footnotetext{
${ }^{1}$ Universidade Estadual de Campinas.

${ }^{2}$ Universidade Estadual de Campinas.

${ }^{3}$ Universidade Estadual de Campinas.

${ }^{4}$ Universidade Estadual de Campinas.

${ }^{5}$ Universidade Estadual de Campinas.

${ }^{6}$ Essa disciplina foi lecionada pela Prof ${ }^{a}$. Dra. Maria Inês Petrucci Rosa, professora da Faculdade de Educação da Universidade Estadual de Campinas.
} 
número possível de integrantes de áreas distintas. Olhamos uns para os outros ligeiramente perdidos, visto que sequer nos conhecíamos, como então teríamos afinidades o suficiente para trabalharmos em grupo e desenvolvermos uma proposta de trabalho juntos?

Para Rosa (2012, p. 402-403):

A identidade docente ligada à formação disciplinar é ponto de partida na formação de professores desenvolvidos nas licenciaturas sob responsabilidade das universidades, cujos currículos engendram práticas culturais e discursivas que reiteram redes de poder em torno da formação específica do seu campo disciplinar.

Dessa maneira, durante nosso percurso formativo dentro da universidade nos encontramos na maior parte do tempo "fechados" em nossos próprios campos disciplinares, nos quais nossas identidades docentes são construídas, o que torna dificultoso pensar "fora" daquilo que se torna nossa zona de conforto. Ainda segundo a autora, "A disciplina escolar se estabiliza como uma espécie de trincheira ou blindagem que ao mesmo tempo em que apoia, isola cada docente em seu campo" (Ibidem, p. 403).

Passado o momento inicial de surpresa nos organizamos em grupos que variavam entre quatro e cinco integrantes. Nosso grupo era composto pelos cursos de enfermagem, letras, filosofia e geografia e realizamos o estágio no Colégio Técnico de Campinas. A proposta de trabalho era que nossos primeiros momentos na escola fossem feito em grupo, que discutíssemos nossas impressões, questionamentos e ideias sempre em conjunto. Posteriormente, acompanharíamos apenas as aulas das nossas disciplinas de referência ${ }^{7}$ enquanto teríamos de formular uma ideia inicial de intervenção na escola que envolvesse as quatro áreas.

Durante grande parte das atividades de estágio encontramos dificuldades de dialogar e organizar nossas ideias. Cada área possuía sua visão de mundo e, aparentemente, todos nós achávamos que nossa visão é a que deveria prevalecer, o que causava conflitos e alguns encontros improdutivos. Acreditamos que essa dificuldade em dialogar e integrar nossos conhecimentos com o objetivo de elaborarmos a intervenção proposta se deu, sobretudo, em função da existência de uma “(...) dinâmica a favor das disciplinas escolares nas práticas curriculares desenvolvidas pelos professores, o que as consolida como instrumento de proteção às identidades docentes, dificultando as possibilidades de integração" (ROSA, 2012, p. 403).

As reuniões semanais de orientação com a professora foram de grande auxílio na resolução desses conflitos, pois ao relatarmos nossas conversas de grupo éramos levamos a pensar a escola como um todo e, dessa forma, como seria um cenário em que seriamos professores e teríamos de lidar com os demais professores da escola que não seriam da mesma área que nós.

A partir de então, o principal questionamento que nos acompanhava em nossas atividades era: se a interdisciplinaridade estava presente na escola durante nossas observações, não seria melhor que a pensássemos e refletíssemos acerca de suas dinâmicas já que também estaria presente no nosso cotidiano enquanto docentes?

Acreditamos que não tínhamos nos dado conta desse cenário até o momento do estágio supervisionado e dessa proposta de trabalho. Mas afinal, qual foi a nossa proposta?

\footnotetext{
${ }^{7}$ As alunas do curso de Enfermagem optaram por acompanhar as aulas de Biologia.
} 


\section{O esforço coletivo e o projeto desenvolvido na escola}

Ao nos inserirmos na cultura do colégio Cotuca, nos deparamos com uma realidade bem particular que não envolvia somente os alunos, mas também os professores e funcionários: a utilização das redes sociais como meio de comunicação.

Os meios de comunicação virtuais, que inicialmente eram vistos como meios informais de comunicação nos quais diversas pessoas poderiam expor da maneira como desejassem suas vidas pessoais, dentro desse colégio tornou-se um dos mais efetivos meios de comunicação, independente do nível hierárquico profissional. Professores, alunos e funcionários comunicamse livremente por meio do Facebook, seja para expor notas de provas, recados, compartilhar informações relevantes da aula, ou até mesmo lembretes de plantões de duvidas.

Dentro dessa característica do Cotuca o grupo optou por, de forma interdisciplinar, explorar esse meio de comunicação disseminado pela escola, pensando em como esse quadro supostamente afetaria a vida de cada individuo envolvido e que espaço as redes sociais estariam ocupando na vida de cada um deles, sobretudo no contexto escolar.

Nesse sentido buscamos relacionar nossas áreas de estudo com a temática das "redes sociais". A principal questão levantada pela área da Biologia foi "qual a importância, vantagens e desvantagens da disseminação das redes sociais no cotidiano e como esse quadro tem afetado a saúde da população?"”.

Essa área trouxe a ideia de que a escassez ou a falta das relações sociais constitui fator de risco à saúde comparado a outros que são comprovadamente nocivos, tais como o fumo, a pressão arterial elevada, a obesidade e a ausência de atividade física. Além disso, relações sociais são suporte no alíviocargas da vida cotidiana.

$\mathrm{O}$ apoio social que as redes proporcionam remete ao dispositivo de ajuda mútua, ressaltando os aspectos positivos das relações sociais: compartilhar informações, auxílio em momentos de crise e a presença em eventos social (ANDRADE, 2002, p. 926).

A constatação de que a interação interpessoal pelas redes favorece comportamentos de monitoramento da saúde, é considerada uma das influências positivas das redes sociais na saúde. Outras influências consideradas são a possibilidade de diálogo e a aproximação de instituições, incluindo as governamentais, com a sociedade. As informações divulgadas a respeito de ações de saúde pública podem auxiliar na melhoria da qualidade de vida do cidadão, seja para a promoção da saúde, seja na prevenção de doenças ou adesão da população às mobilizações de campanhas. Ajudam a mapear problemas de saúde pública, à medida que possibilitam identificar por meio das postagens dos usuários, a escassez de medicamentos, por exemplo.

Por outro lado, há questões críticas no âmbito da saúde pública, tais como encontrar rapidamente informações, identificar sua validade e avaliá-la. Assim como as redes sociais podem ser usadas para que pessoas se organizem, também podem criar resistência a medidas necessárias na área de saúde coletiva.

No âmbito da filosofia foram trazidos ao debate os filósofos alemães Friedrich Nietzsche e Martin Heidegger. Foi questionado o quanto essa vivência virtual pode, de alguma maneira, nos afastar cada dia mais de uma experiência filosófica. A relação que Nietzsche traça entre Filosofia e vida não é apenas uma relação conceitual, mas sim uma relação sinonímica, isto é, Filosofia é vida, Filosofia é experiência vivida. Dessa maneira, a experiência filosófica não se dá no escrever sobre Filosofia ou falar sobre Filosofia, mas sim em viver de maneira filosófica, isto é, fazer da vida um palco de experimento para os pensamentos. Dessa maneira, o diálogo que podemos suscitar com as redes sociais à luz do pensamento nietzschiano resume-se a um questionamento da nossa conduta em tal meio, será que realmente fazemos jus a nossa identidade dentro das redes socais ou, assumimos diferentes personalidades e modos de pensar uma vez que estamos distantes da situação 
penosa que é o olhar do outro? Será que deixamos de experienciar nossos próprios pensamentos e sentimentos substituindo a vivência pelo discurso escrito? E tal discurso, será que realmente através deste conseguimos transmitir integralmente e com eficiência o que estamos pensando ou sentindo?

Em contrapartida, o pensamento heideggeriano estabelece uma relação sinonímica entre filosofia e linguagem, isto é, para Heidegger, Filosofia é logos - palavra de origem grega que significa tanto razão quanto discurso - é linguagem. Só filosofamos quando conseguimos escutar realmente o que o discurso nos diz, ou seja, quando apreendemos de maneira profunda o que cada palavra tem a nos dizer, e para tanto, é essencial que tenhamos um cuidado muito especial ao tratar da linguagem, pois esta não é simplesmente um instrumento para a filosofia, mas sim a maneira própria de filosofar, uma vez que pensamos por meio de palavras.

$\mathrm{Na}$ Geografia, primeiramente trouxemos os estudos de Santos (2002) sobre o que o autor denomina de meio técnico-científico-informacional. Esse período corresponde ao tempo histórico atual e se refere a um momento no qual a técnica, a ciência e a informação, de maneira extremamente relacionadas, são protagonistas na construção e reconstrução do espaço, de modo a determinar ações e normas na sociedade. O autor coloca que o "meio técnico-científicoinformacional é a cara geográfica da globalização" (Idem, p. 239).

Pacheco (2014, p. 305-306), discorrendo acerca desses novos espaços de interação social, nos traz que:

No contexto da vida social contemporânea dos jovens caracterizada pela reordenação do tempo e do espaço observa-se um deslocamento das relações sociais de seus lugares específicos, não modificando essas relações por completo, mas recombinando-as através de novos espaços - por exemplo, as comunicações feitas através do Facebook e os bate papos na internet.

Acreditamos, nesse sentido que, do ponto de vista da Geografia, as técnicas devem ser apropriadas de modo que determinado local desenvolva suas atividades da melhor maneira possível. A utilização da internet e do Facebook como meio de comunicação entre os diversos agentes escolares do Cotuca possibilita que estes se apropriem de uma ferramenta para ressignificarem esses "novos espaços" de Pacheco (Ibdem), não apenas os trazendo para o cotidiano escolar, mas tornando-os peça importante em suas práticas, relações e, sobretudo, comunicação.

As discussões no campo da Letras priorizava a ideia da difusão e influência das redes sociais na vida dos alunos e no cotidiano da escola - sendo elas não apenas meras ferramentas de comunicação, senão uma extensão de mundo e de convívio tão real quanto a sala de aula - e tendo como respaldo a investigação de Luciene Pinheiro de Souza e Vera Lucia Deps, intitulada "A linguagem utilizada nas redes sociais e sua interferência na escrita tradicional: um estudo com adolescentes brasileiros", foi proposto como parte do projeto de intervenção escolar, uma reflexão com os alunos sobre a linguagem escrita enquanto prática social em ambientes virtuais e sua influência sobre as praxes de escrita escolar.

A língua é heterogênea, dinâmica e se apresenta de formas variadas dependendo do contexto de comunicação. Na situação discursiva em que se abordou a língua (nas redes sociais), a norma padrão de escrita é amiúde rompida sem gerar qualquer tipo de discussões, estigmas ou zombaria entre os que escrevem e assim pensar que "A escola não deve se abster do seu papel de ensinar a língua padrão, mas é preciso reconhecer a importância das demais variedades." (Ibidem).

Após termos estabelecido o que cada área iria trabalhar, apresentamos o seguinte tema/questionamento aos alunos: "Qual é o impacto da internet sobre a vida das pessoas e, em especial, dos estudantes?". 
Foi então realizado um debate com a problematização do uso das redes articulado com as áreas do saber, visando identificar e discutir os impactos das redes sociais no cotidiano, especialmente em relação ao ambiente escolar e como as diversas áreas poderiam contribuir para que se tivesse uma ideia geral do quanto esse tema era amplo e poderia ser abordado por diferentes perspectivas - perspectivas essas que os alunos não eram obrigados e incorporarem em sua visão de mundo, mas sim terem noção das variadas possibilidades de se pensar esse tema.

\section{O que essa experiência nos deixou?}

Acreditamos que essa experiência inicial nos permitiu, sobretudo, abrirmos nossos horizontes para além daquilo que se tornou em nosso percurso formativo a nossa zona de conforto: nossa área de formação.

Realizar um trabalho interdisciplinar trouxe muito aprendizado não somente para nós, alunos responsáveis pela realização da proposta, mas também para aqueles que participaram desta reflexão. A execução foi um grande desafio: Ciências Biológicas, Geografia, Letras e Filosofia sendo trabalhadas juntas? O resultado final nos mostrou era possível. Dialogar entre as diversas áreas mostrou-nos que é possível deixar de lado um aprendizado mais fragmentado e específico e mostrar as diversas faces de um mesmo assunto, tornando as reflexões e discussões mais ricas.

Sair da zona de conforto e agregar múltiplas visões sobre um tema foi uma experiência única. As aprendizagens e o desejo de conhecimento foram os principais combustíveis nessa jornada rumo ao desenvolvimento pessoal e profissional. As várias perspectivas das disciplinas sobre determinada temática é importante não apenas aos alunos bem como aos professores.

Precisamos admitir que desenvolver uma aula integrando as diferentes disciplinas escolares foi um desafio estimulante e nos ensinou, principalmente, a pensar além de nossas áreas de formação, o que propiciou uma visão mais ampla sobre, mais especificadamente no caso deste trabalho, as redes sociais. O objetivo era propiciar aos alunos uma construção de um saber crítico-reflexivo, afim de superar uma fragmentação aparentemente existentes entre as disciplinas.

Trabalhar nessa perspectiva gerou um movimento de mudança de atitude em busca de um "para além de nós": para além nossos próprios institutos, colegas de curso e visão de mundo centrada em nossas disciplinas. O resultado foi trabalho em equipe intenso que promoveu amadurecimento e cumplicidade entre os membros do grupo.

\section{Referências}

ANDRADE, G.; VAITSMAN, J. Apoio social e redes: conectando solidariedade e saúde. Ciência \& Saúde Coletiva, n. 7 (4), p. 925-934, 2002.

HEIDEGGER, M. O que é isto, a filosofia. In: Martin Heidegger, Editora Abril, Coleção Os Pensadores, 1984.

NIETZSCHE, F. Além do bem e do mal. Editora Companhia das Letras, 2005. Tradução de Paulo César de Souza.

PACHECO, W. F. C. A geograficidade do ciberespaço: o Facebook como relevância cultural na juventude da sociedade da informação. Congresso Internacional Interdisciplinar em Sociais e Humanidades. Out., 2014. Salvador, BA. Anais. ISSN: 2316-266X. n. 3, v. 1. 
ROSA, M. I. P. Experiências interdisciplinares e formação de professore(a)s de disciplinas escolares: imagens de um currículo-diáspora. Pro-Posições, v. 18, n. 2 (53), maio/ago. 2007.

. Práticas curriculares interdisciplinares no ensino médio na relação com a formação de professores. XVI ENDIPE - Encontro Nacional de Didática e Práticas de Ensino. 2012. UNICAMP, Campinas.

SANTOS, M. A Natureza do Espaço: Técnica e Tempo, Razão e Emoção. 4. ed. 2. São Paulo: Editora da Universidade de São Paulo, 2002.

SOUZA, L. P.; DEPS, V. L. A linguagem utilizada nas redes sociais e sua interferência na escrita tradicional: um estudo com adolescentes brasileiros. II Congresso Internacional TIC e Educação. 2012. Lisboa. Atas.

\section{Sobre os autores}

Jéssica da Silva Rodrigues Cecim é licenciada em Geografia pelo Instituto de Geociências da Unicamp e cursa o bacharelado na mesma instituição. Pesquisa na área de Ensino de Geografia. E-mail: jcecim@gmail.com.

Ráisa Camilo Ferreira é licenciada em Enfermagem pela Faculdade de Enfermagem da Unicamp e possui bacharelado na mesma instituição. Pesquisa na área de Sistematização da Assistência de Enfermagem.

E-mail: raisacf@hotmail.com.

Hellen Angélica Ruiz é licenciada em Enfermagem pela Faculdade de Enfermagem da Unicamp e possui bacharelado na mesma instituição. Pesquisa na área de Enfermagem Pediátrica.

E-mail: hellenruiz@live.com.

André Vinícius Almeida Ribeiro é licenciado em Letras-Português pelo Instituto de Estudos de Linguagem da Unicamp e realiza pesquisas na área de Tradução de Literatura Infantil.

E-mail: a.vinicius.ribeiro@gmail.com.

Adilson Grego Junior é aluno do curso de Filosofia do Instituto de Filosofia e Ciências Humanas da Unicamp.

E-mail: adilsongregojr@gmail.com. 